\title{
A Teoria dos Jogos Empresariais como Estratégia de Ensino Aprendizagem nos Cursos de Administração de Empresas
}

\section{Corporate Games theory as a teaching strategy in Business Administration undergraduate courses}

\author{
${ }^{1}$ Marcello Silva e Santos \\ ${ }^{1}$ Marcos Antonio Ribeiro Andrade \\ ${ }^{1}$ Leticia Souza Romão \\ ${ }^{1}$ Maristela Gonçalves
}

\begin{abstract}
Games have always been used as a simulation tool throughout men's history, starting off from those known as "war games". However, it was reported that they were first used as a learning aid in 1957 in the United States of America. This study aims to demonstrate the importance of business games as a methodology for management-related academic training. This strategy relates to Resourse-Based View (RBV) and Dynamic Capabilities models, used for companies in search of competitive advantage. Plus, today's markets and organizations require value-added, highly competitive-minded professionals. Thus, this study focused in an interesting dilemma: pursuing purely theoretical knowledge or applying practical hands-down action, what should prevail? A bibliographical review was performed in order to bring up recent studies on business games from knowledgeable authors. Then, it was correlated to recent developments in private colleges in the city of Volta Redonda, in where such techniques were applied to recreate a business environment. In terms of research methodology, this study was based on an exploratory analysis of multiple cases, in a descriptive qualitative research format. Initial results show no correlation between massive theoretical knowledge and real world managerial performance. On the other hand, during simulation games it was possible to monitor and constantly verify students abilities and management attitudes, suggesting the method to be very effective in those matters.
\end{abstract}




\section{RESUMO}

Os jogos sempre estiveram presentes na história do homem, tendo surgido como estratégia para simulação de guerra. No entanto, como instrumento de aprendizagem somente foram percebidos em 1957 nos Estados Unidos. O presente estudo tem como objetivo demonstrar a importância da metodologia de ensino por meio dos jogos de empresas para formação gerencial e estratégica dos acadêmicos de Administração, através da Visão Baseada e Recursos (RBV) e das Capacidades Dinâmicas, com ferramentas geradoras de vantagem competitiva, visto que o cenário contemporâneo vem exigindo profissionais que gerem valor e posicionamento de mercado para as organizações. Concentrou-se esse estudo no dilema: conhecimento teórico e desempenho prático, o que deveria prevalecer? Isso foi feito resgatando os estudos feitos por autores de renome sobre o tema Jogos de Empresas. Com isso, estudos demonstram que o jogo simulado, ao recriar um ambiente bem próximo da realidade empresarial, propicia aos alunos novas experiências e novas habilidades, sendo um recurso complementar ao método expositivo adotado pelas Universidades particulares de Volta Redonda. Para o desenvolvimento da pesquisa utilizou-se o método qualitativo descritivo, na forma de um estudo exploratório, com análise de casos múltiplos. Os resultados demonstram que não havia correlação entre altos conhecimentos teóricos e melhores desempenhos na prática, porém o desenvolvimento de conhecimentos, habilidades e atitudes gerenciais estão constantemente presentes durante o processo de treinamento por meio do jogo simulador.

Palavras-chave: Jogos Simulados, Visão Baseada em Recursos, Capacidades Dinâmicas.

\section{INTRODUÇÃO}

Nos últimos anos, as publicações da área de Administração, vêm enfatizando a importância da aprendizagem vivencial para melhor compreensão da prática gerencial. Tal recurso proposto em um jogo amplia o alcance do ensino tradicional, proporcionando, ao acadêmico aprender-fazendo (SAUAIA, 2006). Segundo o autor, a Teoria dos Jogos surge como um modelo educacional com a finalidade de prover uma dinâmica vivencial com grande semelhança do que ocorre no dia a dia de uma organização. Os primeiros modelos de simulações surgiram nos treinamentos militares, onde os jogos de tabuleiros simulavam o exército, determinando estratégias e táticas aplicáveis em batalhas reais dos prussianos (GRAMIGNA,1994). Porém, Marion e Marion (2006), relatam que como instrumento de aprendizagem, os jogos simulados foram percebidos pela primeira vez nos Estados Unidos, na Universidade de Washington, em 1957, dentro de um programa de treinamento da American Management Association Academy.

No Brasil, os jogos de simulação empresarial surgiram na década de 1970, como uma metodologia para aperfeiçoamento do recurso ensino-aprendizagem. Além disso, os jogos de simulação empresarial ajudam a preencher as necessidades dos alunos de estarem diretamente envolvidos com as decisões de empresas altamente competitivas em seu mercado, estimulando a criatividade empresarial e o trabalho em grupo, competências tão necessárias ao administrador moderno (KNABBEN E FERRARI, 2008). Entretanto, os modelos convencionais de ensino, com aulas estritamente expositivas, ainda perduram em meio às universidades particulares do país, inclusive em Volta Redonda, tendo em vista que os cursos de Administração enfatizam o conhecimento teórico, que ainda que importante, acaba dissociando a teoria da prática.

O presente estudo visa analisar o impacto que a Teoria dos Jogos, como modelo estratégico, exerce na formação do administrador, avaliando se os benefícios elencados pelos teóricos da área serão auferidos com os resultados obtidos após participação em uma simulação empresarial. Nesse sentido, procura-se demonstrar a importância da metodologia de simulação estratégica no aprimoramento da capacidade de tomada de decisões através de cooperação e trabalho em grupo, sugerindo-se que tal recurso deva ser não somente uma disciplina 
complementar, mas obrigatória na matriz curricular das instituições. Com isso, estar-se-iam atendendo de maneira eficaz as expectativas dos novos mercados com profissionais que possuam habilidades fundamentais para a prática gerencial. Portanto, a relevância deste estudo para a sociedade deve-se ao fato de se permitir oferecer ao mercado gestores mais preparados e com poder de autoconhecimento, para que possam exercer a tomada de decisões com responsabilidade, aplicando ou relacionando o conhecimento obtido na universidade no âmbito empresarial.

\section{ORIGEM E EVOLUÇÃO DA TEORIA DOS JOGOS:}

A Teoria dos Jogos é usualmente explicada por meio de uma fábula conhecida como Dilema dos Prisioneiros, que aborda a situação de dois encarcerados acusados do mesmo crime. A polícia tem evidências para mantê-los preso por um ano, porém não para condená-los. Assim, eles são colocados em celas separadas para que não haja acordos prévios (KAY, 1996). O dilema é um modelo de jogo não cooperativo com decisões simultâneas, onde um não sabe nada sobre a decisão do outro, permitindo algumas possibilidades de ganhos e perdas conforme quadro 1 .

\begin{tabular}{|c|c|c|}
\hline & $\begin{array}{l}\text { Pedro Confessa } \\
\text { (Deserta) }\end{array}$ & Pedro Não Confessa (Coopera) \\
\hline $\begin{array}{l}\text { João Confessa } \\
\text { (Deserta) }\end{array}$ & $\begin{array}{l}2 \text { anos } \\
2 \text { anos }\end{array}$ & $\begin{array}{c}5 \text { anos } \\
\text { Liberdade (0) }\end{array}$ \\
\hline $\begin{array}{l}\text { João Não Confessa } \\
\text { (Coopera) }\end{array}$ & $\begin{array}{l}\text { Liberdade (0) } \\
5 \text { anos }\end{array}$ & $\begin{array}{l}1 \text { ano } \\
1 \text { ano }\end{array}$ \\
\hline
\end{tabular}

Quadro 1 - Matriz Dilema dos Prisioneiros

Fonte: Marinho (2011)

O Dilema nos remete ao jogo, por abordar decisões como calar ou falar, correspondendo para todos os efeitos a cooperar ou não cooperar (desertar), sendo uma decisão binária, racional, sem uma única operação matemática (MARINHO, 2011). Com a finalidade de prever os movimentos dos outros jogadores, concorrentes ou aliados, através dessa teoria os jogadores se posicionam de forma a obter os melhores resultados, entendendo a lógica na hora da decisão e percebendo se é possível haver colaboração entre os mesmos (ALMEIDA, 2006). O Dilema nos mostra que em cada decisão pode-se satisfazer o seu próprio interesse ou atender o interesse do grupo, com rivalidade pura e lucro zero.

Baseando-se em um conjunto de informações que orientam na tomada de decisão, a fim de maximizar os resultados a cada estratégia, a teoria dos jogos divide-se em dois ramos: jogos cooperativos e não cooperativos. O desejo de maximizar o resultado do coletivo é definido como cooperativos, enquanto nos jogos não cooperativos, o indivíduo se preocupa em maximizar seus próprios resultados, dentro das regras do jogo, independente do resultado coletivo (SAUAIA; KALLÁS, 2007). O acesso aos simuladores no Brasil e a flexibilidade do Ministério da Educação para abertura de cursos superiores, foram fatores determinantes para consolidação do método de simulação empresarial no meio acadêmico brasileiro. Com essa política, as universidades se depararam com a preocupação em incluir disciplinas de integração de teoria à prática como diferencial para os novos acadêmicos (MARION E MARION, 2006).

\section{CONCEITUAÇÃO DE TEORIA DOS JOGOS}

Para Osborne e Rubistein (1994), a Teoria dos Jogos é um conjunto de ferramentas que auxilia no entendimento dos fenômenos observados quando tomadores de decisões interagem entre si, levando em conta capa- 
cidades, conhecimentos e expectativas dos diversos jogadores. É um método matemático que faz menção aos processos de tomada de decisão por participantes que reconhecem sua interação mútua do tipo: "penso que você pensa o que eu penso sobre você mesmo” (MARINHO, 2011 p.41). Goldschmidt (1977, p.43) definiu o jogo simulado como "um exercício seqüencial de tomada de decisões, estruturado dentro de um modelo de conhecimento empresarial, em que os participantes assumem o papel de administradores de empresas." O método baseia-se na abordagem vivencial, envolvendo os acadêmicos no processo, permitindo a aplicação de conhecimentos adquiridos na teoria pela experimentação do sentimento real de sucesso ou fracasso tornando o aprendizado mais dinâmico e motivante, visto que os alunos são agentes ativos do processo (MARION E MARION, 2006).

Complementando, Sauaia (2006) corrobora quando diz que Jogos de Empresas representam um método educacional com a característica de prover uma dinâmica vivencial com grande semelhança com que ocorre no dia a dia de uma organização. Baseando-se na leitura e compreensão de um caso empresarial apresentado com pontos fortes e fracos a serem identificados no ambiente interno e oportunidades e ameaças do ambiente externo. Tal metodologia de ensino pode ser denominada jogos de empresas, jogos de negócios, jogos gerenciais, simulação empresarial, simulação de gestão, gestão simulada e simulação gerencial. Os quais serão tratados nesse estudo como sinônimos, no que tange ao recurso didático teoria dos jogos (MARION E MARION, 2006).

Para Gramigna (1994), quatro características são essenciais nos jogos de empresas. A primeira trata das possibilidades de modelar a realidade das empresas, onde as atividades desenvolvidas nos jogos devem ser semelhantes às vivências do participante. A segunda refere-se à definição de papéis, onde o comportamento do participante será determinado de acordo com o tipo que exerce. A terceira trata das regras do jogo, onde o facilitador deve apresentar claramente as regras, e a quarta característica que trata das condições para que o jogo seja atrativo e envolvente, onde o facilitador deve entusiasmar o grupo antes de começar o jogo.

A aprendizagem vivencial faz com que o indivíduo se desenvolva de uma forma duradoura, mudando seu interior e suas percepções, seu modo de agir e pensar ou uma combinação de todos os elementos. E que tal aprendizagem sendo bem classificada e organizada por vários tipos de autores, permite aos facilitadores adquirirem uma maior compreensão e interesse na sua eficiência (SAUAIA, 1995). A técnica, portanto, amplia o alcance do ensino tradicional. Esse "aprender fazendo" propõe ao participante uma importante interação com seu objeto de estudo, estimulando o raciocínio lógico e a busca pelo autoconhecimento. Com isso os mecanismos que atuam sobre o sistema cognitivo são exercitados em sua influência em processos de tomada de decisão, trazendo como resultado decisões com mais coerência e responsabilidade, pois combinam a razão e emoção. Isso faz emergir uma importante conexão-chave nas organizações, inexplorada no ensino expositivo (SAUAIA, 2006).

Fedichina, Nagamatsu e Gozzi (2006) estão em consonância com Sauaia (2006) quando afirmam que os jogos simulados possibilitam ao acadêmico a oportunidade de simulações como: tomar decisões, trabalhar em equipe, montar estratégia, negociar, desenvolver o espírito de liderança e outros. Os autores relatam ainda que os jogos empresariais possibilitam ao acadêmico a oportunidade de desenvolverem capacidades e habilidades necessárias para seu crescimento individual e coletivo (espírito de equipe, valores morais, autodisciplina). Kallás (2003) analisa as vantagens da utilização de jogos simulados no processo de aprendizagem e sintetiza esse processo analítico fazendo uma avaliação dos jogos empresariais de acordo com os sete princípios da boa prática em educação prevalentes no ensino superior. $O$ autor então relaciona cada um desses princípios essenciais com os possíveis resultados obtidos da utilização de jogos simulados. A súmula dessa análise está ilustrada no quando 2. 


\begin{tabular}{|l|l|}
\hline Prática & Como os Jogos Simulados tratam o assunto \\
\hline $\begin{array}{l}\text { 1. Encorajar o contato do } \\
\text { estudante com a faculdade }\end{array}$ & $\begin{array}{l}\text { Os jogos simulados estimulam comportamentos pessoais que encorajam o } \\
\text { contato do estudante com a faculdade ou universidade na medida em que a } \\
\text { preparação para as “rodadas” do jogo se mostra imprescindível }\end{array}$ \\
\hline $\begin{array}{l}\text { 2. Encorajar cooperação entre } \\
\text { estudantes }\end{array}$ & $\begin{array}{l}\text { A formação de grupos para a participação dos jogos estimula a cooperação } \\
\text { entre alunos }\end{array}$ \\
\hline 3. Encorajar aprendizado ativo & $\begin{array}{l}\text { Como os jogos simulados demandam a demonstração de habilidades, muitas } \\
\text { vezes a busca de conhecimentos específicos é demandada e o aprendizado } \\
\text { ativo é necessário por parte dos estudantes }\end{array}$ \\
\hline $\begin{array}{l}\text { 4. Fornecer feedback } \\
\text { instantâneo }\end{array}$ & $\begin{array}{l}\text { O feedback é oferecido na forma dos resultados das simulações. Da mesma } \\
\text { forma, a atuação do professor fornecendo feedback aos alunos e grupos é } \\
\text { atividade incentivada }\end{array}$ \\
\hline $\begin{array}{l}\text { 5. Enfatizar engajamento de } \\
\text { tempo dedicado }\end{array}$ & $\begin{array}{l}\text { A participação nos jogos simulados demanda a dedicação não só nas } \\
\text { "aulas”, onde as decisões são tomadas, mas também nos intervalos entre as } \\
\text { rodadas de decisão, onde é feita a preparação preliminar }\end{array}$ \\
\hline $\begin{array}{l}\text { 6. Comunicar altas } \\
\text { expectativas }\end{array}$ & $\begin{array}{l}\text { A preparação para o jogo é fundamental. Neste momento são acertados os } \\
\text { critérios para a pontuação nos jogos e o método de avaliação do aprendizado }\end{array}$ \\
\hline $\begin{array}{l}\text { 7. Respeitar a diversidade } \\
\text { de talentos e modos de } \\
\text { aprendizagem }\end{array}$ & $\begin{array}{l}\text { Cada estudante pode estudar da sua maneira. Os jogos privilegiam a maneira } \\
\text { pela qual o conhecimento é demonstrado, na forma de decisões }\end{array}$ \\
\hline
\end{tabular}

Quadro 2 - Avaliação dos jogos simulados de acordo com os setes princípios da boa prática na educação de ensino superior. Fonte: Gamson apud Kallás (2003)

\section{JOGOS DE EMPRESAS COMO ESTRATÉGIA DE ENSINO}

A globalização trouxe, entre outros fatores, a mudança dos hábitos e exigências dos clientes e o aumento da concorrência em diversos setores, que fazem com que o estabelecimento de uma estratégia coerente seja cada vez mais importante para aquelas organizações que visam bom posicionamento no mercado em que atuam (ALVARENGA OLIVEIRA, 2011). Segundo Marion e Marion (2006), a política do Ministério da Educação de flexibilização para a abertura de cursos superiores, aliada a novas diretrizes curriculares, também exigiu que as Universidades se preocupassem com a inclusão de disciplinas de integração da teoria à prática, trazendo para as mesmas um novo posicionamento no mercado.

De acordo com Oliveira (2009), estratégia é o estabelecimento de caminhos, cursos, programas de ação que deverão ser seguidos para que se alcancem os objetivos ou resultados estabelecidos por organizações ou pessoas, visando antecipação do futuro e como chegar de uma melhor maneira até ele. A estratégia coloca as organizações à frente de seus concorrentes, fornecendo valores mutáveis à comunidade. Fornecer algo novo, captar e formar oportunidades de mercado, melhorando a qualidade do serviço é atualmente desafiador e recompensador (ABBAS, 2000). Para Roberto Vatan (2003), os jogos de empresa, como estratégia para as universidades, devem ser aplicados dentro de um contexto de aprendizagem, sob o enfoque da educação centrada no sujeito, através da perspectiva construtivista de trabalhos equipe, onde o professor assume a postura de facilitador do processo com objetivos previamente estabelecidos.

Os Jogos Simulados trazem para as universidades as vantagens de aprendizagem participativa, desenvolvimento de habilidades gerenciais, além de permitir observar atitudes empreendedoras em coordenadores, professores e acadêmicos (SAUAIA, 2006). A fim de justificar o uso dos Jogos de Empresas como recurso di- 
ferencial nas universidades, Titton (2006) apresenta uma relação comparativa e a matriz SWOT e os principais aspectos do jogo apresentados no quando 3 :

\begin{tabular}{|c|c|}
\hline Pontos Fortes & Pontos Fracos \\
\hline $\begin{array}{l}\text { 1. Proporcionam o conhecimento da natureza } \\
\text { sistêmica do negócio; } \\
\text { 2. Possibilitam a compreensão da formação de } \\
\text { equipes e do comportamento inter pessoal; } \\
\text { 3. Utilizam o fator "competição" para motivar os } \\
\text { participantes; } \\
\text { 4. Possibilitam a compreensão da necessidade de } \\
\text { informações para melhorar o processo de tomadas de } \\
\text { decisão; } \\
\text { 5. Possibilitam a aprendizagem da avaliação de riscos } \\
\text { e da administração do tempo; } \\
\text { 6. Possibilitam o experimento de novos tópicos em } \\
\text { sala de aula; } \\
\text { 7. Possibilitam a identificação da necessidade da } \\
\text { abordagem de novos tópicos em sala de aula; } \\
\text { 8. Proporcionam uma ferramenta para o } \\
\text { “desenvolvimento de papéis” diferente das funções } \\
\text { desempenhadas no dia-a-dia; } \\
\text { 9. Possibilitam simular diferentes negócios e as } \\
\text { habilidades específicas para cada tipo de negócio; } \\
\text { 10. Proporcionam flexibilidade para trabalhar com } \\
\text { diferentes níveis de habilidades }\end{array}$ & $\begin{array}{l}\text { 1. Dependem de software e hardware; } \\
\text { 2. Necessitam de facilitadores com conhecimentos } \\
\text { básicos de informática; } \\
\text { 3. Necessitam de tempo para os participantes aprender } \\
\text { a jogar o jogo; } \\
\text { 4. Possuem recursos limitados no que tange a espaço } \\
\text { físico, equipamentos e suporte docente; } \\
\text { 5. Necessitam de tempo para desenvolver de forma } \\
\text { satisfatória todas as etapas de um jogo: introdução, } \\
\text { desenvolvimento e avaliação; } \\
\text { 6. Abordam, em sua maioria, somente variáveis } \\
\text { quantificáveis } \\
\text { 7. Possuem modelagens muito simplificadas; } \\
\text { 8. Processam as decisões somente após todas as } \\
\text { equipes apresentarem o seu conjunto de decisões; } \\
\text { 9. Apresentam, raramente, situações de tomada } \\
\text { de decisão que envolvam situações estratégicas e } \\
\text { operacionais } \\
\text { 10. Centralizam, muitas vezes, dentro das equipes, } \\
\text { informações / decisões e podem provocar isolamento } \\
\text { de participantes; }\end{array}$ \\
\hline Oportunidades & Ameaças \\
\hline $\begin{array}{l}\text { 1. Avanços em termos de software, hardware e } \\
\text { redes possibilitam o estabelecimento de "escritórios } \\
\text { virtuais"; } \\
\text { 2. Desenvolvimento de simulações específicas para } \\
\text { determinados setores ou negócios; } \\
\text { 3. Desenvolvimento de jogos multinacionais através } \\
\text { da internet; } \\
\text { 4. Desenvolvimento de jogos "individuais" que } \\
\text { possibilitem a auto-avaliação; } \\
\text { 5. Utilização de jogos de empresa em programas de } \\
\text { recrutamento e seleção. }\end{array}$ & $\begin{array}{l}\text { 1. Custos crescentes para o desenvolvimento, } \\
\text { programação e testes; } \\
\text { 2. Dificuldade em mensurar a eficiência do } \\
\text { aprendizado; } \\
\text { 3. Complexidade dos modelos pode superar o } \\
\text { conhecimento e a confiança do facilitador; } \\
\text { 4. Restrições de tempo, pessoas e recursos físicos; } \\
\text { 5. Risco de violação de segurança dos sistemas. }\end{array}$ \\
\hline
\end{tabular}

Quadro 3 - Matriz SWOT e os principais aspectos do jogo apresentados

Fonte: adaptado de Johnsson apud Titton (2006)

\section{A TEORIA RESOURCE-BASED VIEW (RBV) OU VISÃO BASEADA EM RECURSOS (VBR)}

Para Oliveira et al (2007), sobreviver e prosperar não é tão fácil em ambientes de acirrada competição, fazendo-se necessário que sejamos capazes de nos ajustar com maior rapidez e eficácia, às crescentes ameaças e oportunidades que surgem nos ambientes em crescente transformação. Assim, a teoria Resource-Based View (RBV) ou Visão Baseada em Recursos surge como um processo estratégico de tomada de decisões que gera valor para mercados dinâmicos, visto que apresenta-se como uma teoria que permite compreender de que forma a vantagem competitiva é alcançada e como é sustentada (MARTINS E PEREIRA, 2011). 
De acordo com Barney e Hesterly apud Martins e Pereira (2011), recursos são ativos tangíveis e intangíveis que utilizamos para criar e implementar estratégias, e propõe ainda que recursos geradores de vantagem competitiva devem atender a condições básicas, como: 1) Possuírem valor; 2) Serem raros; 3) Difíceis de imitar; e 4) Difíceis de substituir. No potencial de valor os recursos devem explorar oportunidades ou neutralizar ameaças de tal forma que a organização obtenha redução de custos ou incremento de receitas; Quanto a serem raros, os recursos devem ser acessíveis a poucas empresas competidoras para garantir uma vantagem sustentável (BARNEY apud TIERGATEN E ALVES, 2008).

Ainda o mesmo autor, salienta que os recursos devem ser imperfeitamente imitáveis pelos concorrentes potenciais, sendo necessária a criação de barreiras essenciais como: condição histórica, ambigüidade única e complexidade social e que para que o recurso gere uma vantagem competitiva sustentável é necessário que não haja substitutos estratégicos, sendo tal recurso insubstituível. Os ativos intangíveis referem-se não somente à reputação, patentes ou relacionamentos, mas também às habilidades intelectuais mais complexas e específicas, que são difíceis de mensurar e imitar (PEREIRA E FORTE, 2008).

Assim, quando uma organização privilegia a aprendizagem sobre o ensino, como atividades complementares e vinculadas, inseparáveis no processo educacional, através dos jogos simulados, ela desafia os acadêmicos a demonstrarem suas habilidades gerenciais, os tornando capazes de agregar valor às organizações (SAUAIA, 2006). O mesmo autor, os jogos simulados geram a máxima diversidade de fatores, criando oportunidades para que as diferenças produzam conflitos, estimulando a criatividade, desafios enriquecedores do processo educacional.

Para Antunes (2000), os ativos intangíveis resultam em benefícios para a organização em substituição aos demais recursos (trabalho, capital e terra), onde os possuidores do conhecimento detêm o poder, uma vez que é um recurso ilimitado, aperfeiçoado de acordo com as necessidades de desenvolvimento, impulsionando mudanças por meio de criatividade e inovações. Assim, através dos jogos simulados, as organizações que desenvolvem habilidades e competências e aperfeiçoam as capacidades de seus acadêmicos, formam profissionais preparados para desempenhar suas funções e tomar decisões que melhor atendam as necessidades do mercado que atuam (SOUZA; CHAGAS E SILVA, 2009).

\section{DYNAMIC CAPABILITIES OU CAPACIDADES DINÂMICAS}

O conceito de Dynamic Capabilities ou Capacidades Dinâmicas foi desenvolvido para responder aos desafios da obtenção de vantagem competitiva, criando e capturando riquezas em ambiente de rápida mudança tecnológica (TEECE ET AL, 2007). Logo, deve-se procurar estudar as relações entre os processos de tomadas de decisões, ações empreendidas e suas conseqüências para a organização em termos da formação, conservação e destruição de recursos. (VASCONCELOS E CYRINO, 2000). Segundo Tecce, Pisano e Shuen (1997) o termo “capacidades” enfatiza o papel da administração estratégica em adaptar, integrar e reconfigurar habilidades organizacionais, bem como recursos e competências funcionais. E que “dinâmicas” refere-se à capacidade de renovar competências, tendo em vista as mudanças no ambiente de negócios.

Para os mesmos autores, é possível identificar capacidades dinâmicas dentro de uma organização através de três categorias: processos, posição e trajetória. Onde processos organizacionais referem-se ao modo como as atividades são realizadas dentro da organização, suas rotinas, padrões de prática e aprendizagem; posição referese aos seus ativos tecnológicos, propriedade intelectual, ativos complementares, e suas relações com clientes e fornecedores; trajetória são as alternativas estratégicas disponíveis para a empresa.

Assim, uma organização que oferece aos seus clientes a possibilidade de complementação do aprendizado expositivo, se utiliza de recursos simuladores para trazer um novo modelo de profissional para o mercado. Para Teece e Pisano (1994), a aprendizagem é vista como um processo que permite tarefas repetidas e experimenta- 
ção para a obtenção de um melhor desempenho e rápida identificação de oportunidades. Reforçando, ainda, que capacidades precisam ser construídas continuamente.

A capacidade dinâmica enfatiza o desenvolvimento de capacidades gerenciais que, além de difíceis de imitar, assim como desenvolvimento de processos, tecnologias e propriedade intelectual, incorporam a aprendizagem organizacional (TEECE E PISANO, 1997).

Portanto, para Marion e Marion (2006) a prática da simulação se mostra como um recurso que gera propriedade intelectual, estimulando os acadêmicos a exercitar habilidades importantes ao seu desenvolvimento, trabalhando com intuição e raciocínio, altamente importantes no mundo dos negócios.

A teoria dos jogos, surge como uma possibilidade a ser exercitada, podendo ser vista como um resultado da habilidade intelectual dos administradores para jogar o jogo, sendo uma das construções de capacidades dinâmicas (TEECE; PISANO; SHUEN, 1997).

Para Marion e Marion (2006), nos jogos simulados são desenvolvidas habilidades na tomada de decisão em ambientes de incerteza; propiciando a interpretação de relatórios contábeis, econômicos e financeiros, incluindo avaliação de resultado e desempenho, e o trabalho sob pressão.

A capacidade dinâmica traz para o acadêmico a capacidade de criar, expandir ou modificar a base de recursos, permitindo a ampliação de seus negócios considerados maduros, a entrada em mercados novos ou desconhecidos, ocasionando crescimento interno da organização.

Para o desenvolvimento das capacidades é necessário que as organizações vejam nos jogos simulados um fator que eleva o desenvolvimento das pessoas e de outras organizações, dando-lhes o poder de decisão, uma vez que este poder é baseado em informações e conhecimentos (SOUZA, CHAGAS, SILVA, 2009).

\section{METODOLOGIA}

Quanto à tipologia de trabalho, pode o mesmo ser considerado como uma pesquisa-diagnóstico, onde procura-se explorar os jogos simulados e suas vantagens para os acadêmicos e organização.

Segundo Roesch (1996, p.64) “a Pesquisa-diagnóstico propõe-se levantar e definir problemas, explorar o ambiente. O diagnóstico, normalmente, reporta-se a uma situação, em um momento definido.” Para contemplar a questão de pesquisa apresentada, o estudo tem caráter exploratório e descritivo visto que o intuito é analisar os resultados obtidos na aplicação dos jogos simulados em diferentes amostras por diferentes autores e seus benefícios, objeto de investigação desse estudo.

Segundo Richardson (1999, p.35), “a pesquisa exploratória tenta identificar possíveis relações causa-efeito, submetendo um ou mais grupos experimentais a um ou mais tratamentos e comparando o resultado obtido.” O caráter descritivo "tem como objetivo primordial a descrição das características de determinada população. Pode também estabelecer correlações entre variáveis e definir sua natureza” (VERGARA, 2009, p.42).

Do ponto de vista de procedimentos técnicos, a pesquisa é bibliográfica, tendo sido feita com livros e artigos científicos, que de acordo com Vergara (2009, p.43) considera-se pesquisa bibliográfica aquela "desenvolvida com base em material publicado em livros, revistas, jornais, redes eletrônicas, isto é, material acessível ao público em geral.” Quanto ao método da pesquisa utilizou-se o estudo de casos múltiplos, com o intuito de fortalecer e enriquecer a descoberta original, demonstrando a importância dos jogos simulados no desenvolvimento de diferentes competências. 
Estudo de caso é uma investigação empírica que investiga um fenômeno dentro de seu contexto de vida real, especialmente quando os limites entre o fenômeno e o contexto não estão claramente definidos (Yin, 2007, p. 32).

O mesmo afirma ainda que "estudos de caso único e de casos múltiplos, na realidade, são nada além do que duas variantes dos projetos de estudo de caso" (Yin, 2007, p.33). Tais dados foram coletados de forma secundária, visto que os dados utilizados para tal análise foram extraídos da literatura conforme quadro 4, 5 e 6, onde as variáveis analisadas, foram os benefícios proporcionados pelo jogo na formação de competências, conhecimentos, habilidades e atitudes.

Quanto à forma de abordagem, o estudo é qualitativo, ao analisar os resultados obtidos em diferentes estudos sobre jogos simulados, podendo ser caracterizada "como a tentativa de uma compreensão detalhada dos significados e características situacionais apresentadas pelos entrevistados, em lugar da produção de medidas quantitativas de características ou comportamentos” (RICHARDSON, 2007; p. 90). Na análise dos resultados foi utilizada a análise de conteúdo que segundo Richardson (2007 p. 224), "trata-se de compreender melhor um discurso, de aprofundar suas características (gramaticais, fonológicas, cognitivas, ideológicas e etc) e extrair os momentos mais importantes. Portanto, deve basear-se em teoria relevante que sirvam de marco de explicação para as descobertas do pesquisador.

\section{ANÁLISE DE CASOS}

Os dados apresentados neste estudo foram obtidos por meio de uma revisão do referencial teórico existente sobre o tema analisado neste trabalho, contendo as principais informações necessárias: Autor, estratégia, método e resultado; conforme quadro 4, 5 e 6.

\begin{tabular}{|l|l|}
\hline AUTOR & Antônio Carlos A Sauaia \\
\hline OBJETIVO & $\begin{array}{l}\text { Demonstrar se os conhecimentos teóricos, por si só, garantem aos acadêmicos desempenho } \\
\text { superior na gestão simulada. }\end{array}$ \\
\hline MÉTODO / & $\begin{array}{l}\text { Foram estudados cerca de } 160 \text { alunos de graduação em Administração de Empresas e } \\
\text { Ciências Contábeis (2002) da FEA/USP. Organizados em turmas de 41, 56 e 66 oficialmente } \\
\text { matriculados nos horários de 7:30h, 9:20h e 21:20h respectivamente. Foram aplicados } \\
\text { testes de múltipla escolha preparados com 10 questões extraídas do Provão 2001 para } \\
\text { apurar o nível de conhecimento teórico adquiridos no curso de graduação, onde na apuração } \\
\text { das notas objetivas, cada resposta errada anulava uma certa, a fim de reduzir os "chutes". } \\
\text { ESTRATÉGIA } \\
\text { foram esclarecidas pelo professor, onde mostrou-se que a maioria dos alunos não se sentia } \\
\text { preparado para o “teste drive”, mesmo sem valer nota. Após os resultados experimentais, } \\
\text { os acadêmicos foram desafiados em uma prova escrita de aplicação dos conhecimentos de } \\
\text { jogos de empresas, consistindo em um conjunto de decisões pré-estabelecidas que deveriam } \\
\text { ser transcritas em um formulário. Depois de calculado a média aritmética das três avaliações } \\
\text { de conhecimentos, todos em cada classe foram classificados em ordem decrescente de notas } \\
\text { individuais e organizados em grupos de } 5 \text { ou 6 alunos para gerenciar as empresas simuladas. }\end{array}$ \\
\hline RESULTADO & $\begin{array}{l}\text { Não se observou qualquer correlação significativa entre o desempenho individuais dos alunos e } \\
\text { o desempenho dos grupos, sugerindo que conhecimentos individuais superiores memorizados } \\
\text { nas disciplinas tradicionais não asseguram desempenho superior nas organizações. }\end{array}$ \\
\hline
\end{tabular}

Quadro 4: Elaborado pelos autores

Fonte: Sauaia (2006)

Assim, o estudo mostra que conhecimento individual (prova objetiva) e os jogos simulados são atividades distintas quanto ao resultado produzido, demonstrando a importância da disciplina à matriz da graduação, desenvolvendo competências (conhecimento, atitudes e habilidades gerenciais) como fatores complementares à aprendizagem. 


\begin{tabular}{|l|l|}
\hline AUTOR & Murilo Alvarenga Oliveira \\
\hline OBJETIVO & $\begin{array}{l}\text { Verificar se os melhores alunos serão os melhores gestores e a relação entre conhecimento } \\
\text { teórico e desempenho gerencial num jogo simulado. }\end{array}$ \\
\hline MÉTODO/ & $\begin{array}{l}\text { Foi selecionada uma amostra com 134 alunos, que formaram 24 grupos numa disciplina do curso } \\
\text { ESTRATÉGIA Administração. Os grupos formados participaram de um jogo simulado durante 04 meses. } \\
\text { Assim, foram organizadas 04 turmas ao longo de 2007 e 2008. Os testes foram realizados em } \\
\text { três etapas, sendo a primeira a aplicação de teste de conhecimento com o objetivo de identificar } \\
\text { o nível de conhecimento individual dos participantes, e dividi-los em grupos homogêneos. } \\
\text { Posteriormente, avaliou-se o desempenho do grupo na prática gerencial (jogos simulados) e por } \\
\text { fim avaliaram-se a diferença entre as médias dos desempenhos dos indivíduos no grupo. Após a } \\
\text { segunda etapa, onde foram obtidos os resultados da simulação, realizou-se um teste de hipótese } \\
\text { com o intuito de verificar a existência ou não de diferença entre os resultados. }\end{array}$ \\
\hline RESULTADO & $\begin{array}{l}\text { Comprovou-se a hipótese de que o conhecimento teórico individual não possui qualquer } \\
\text { correlação com o sucesso na prática gerencial, visto que a presença de grupos de "baixo” } \\
\text { conhecimento teórico individual obtiveram um dos melhores desempenhos na prática } \\
\text { gerencial, apresentando desempenho superior ao grupo tido como melhor grupo em nível } \\
\text { de conhecimento individual de seus integrantes, entre outras diferenças. }\end{array}$ \\
\hline
\end{tabular}

Quadro 5: Elaborado pelos autores

Fonte: Alvarenga Oliveira (2009)

Assim, o quadro 5 reforça o resultado encontrado por Sauaia em pesquisa anterior, demonstrado no quadro 4, com o mesmo ou aproximado questionamento, demonstrando a inexistência de correlação entre o conhecimento teórico elencado na academia e o desempenho na prática gerencial aplicada nos jogos simulados. Porém, observa-se em ambos os quadros que o conhecimento recebido nas organizações não é suficiente para garantir o sucesso dos acadêmicos na prática gerencial.

\begin{tabular}{|l|l|}
\hline AUTOR & Gustavo Motta \\
\hline OBJETIVO & $\begin{array}{l}\text { Analisar qual a percepção, dos alunos de graduação e pós-graduação em Administração, } \\
\text { a respeito dos jogos no processo de aprendizagem. }\end{array}$ \\
\hline MÉTODO / \\
ESTRATÉGIA & $\begin{array}{l}\text { Foram sujeitos desse estudo } 72 \text { alunos dos dois últimos períodos do curso de graduação } \\
\text { em Administração e em cursos de pós-graduação em Administração. Os procedimentos } \\
\text { foram realizados de novembro de } 2008 \text { a janeiro de 2009, onde inicialmente o simulador } \\
\text { de jogos foi apresentado a turma pelo moderador que se encarregou de responder às } \\
\text { dúvidas dos mesmos e proceder a divisão dos grupos, formados por } 4 \text { ou } 5 \text { membros, } \\
\text { agrupados de acordo com os estilos de aprendizagem definido pelo Inventário dos Estilos } \\
\text { de Aprendizagem. No segundo encontro as equipes analisavam cenários e tomavam } \\
\text { decisões para dois trimestres da simulação, com o objetivo de simular um ano completo } \\
\text { (quatro trimestres). Os resultados eram discutidos entre os jogadores com intermédio } \\
\text { dos moderadores e ao final cada aluno respondia um questionário não estruturado } \\
\text { de autopreenchimento, contendo duas questões de respostas abertas que os alunos } \\
\text { respondiam com base na experiência vivida sobre a percepção de um jogo de empresa e } \\
\text { a contribuição do mesmo para o aprendizado. }\end{array}$ \\
\hline RESULTADO & $\begin{array}{l}\text { Conclui-se que o jogo corrobora com a maioria das pesquisas já desenvolvidas na área } \\
\text { de que há um auxílio maior no desenvolvimento de habilidades técnicas e humanas e } \\
\text { menor para habilidades conceituais, no entanto verifica-se que o simulador permite que } \\
\text { as decisões sejam lançadas sem embasamento teórico. }\end{array}$ \\
\hline
\end{tabular}


Os resultados obtidos nas pesquisas utilizadas para o estudo de caso objetivaram identificar as similaridades nos resultados alcançados pelos autores que evidenciam os jogos simulados como método de ensino nas organizações. Segundo Bardin (1977, p. 104), a unidade de registro "é a unidade de significação a codificar e corresponde ao segmento de conteúdo a considerar como unidade de base, visando à categorização” na qual se pode verificar a similaridades em relação ao conhecimento e desempenho nos jogos de empresa conforme apresentado no quadro 7.

\begin{tabular}{|c|c|c|c|}
\cline { 2 - 4 } \multicolumn{1}{c|}{} & $\begin{array}{c}\text { Murilo Alvarenga } \\
\text { Oliveira (2009) }\end{array}$ & Gustavo Motta (2010) & $\begin{array}{c}\text { Antônio Carlos A } \\
\text { Sauaia (2006) }\end{array}$ \\
\hline $\begin{array}{c}\text { Conhecimento } \\
\text { teório X Prática } \\
\text { Gerencial }\end{array}$ & Correlação inexistente & Correlação inexistente & Correlação inexistente \\
\hline Atitude & $\begin{array}{c}\text { Desenvolvimento de } \\
\text { comportamento gerencial }\end{array}$ & $\begin{array}{c}\text { Permite a reavaliação } \\
\text { das atitudes e } \\
\text { comportamento gerencial }\end{array}$ & $\begin{array}{l}\text { Aprimora nos participantes } \\
\text { o comportamento gerencial }\end{array}$ \\
\hline Competência & $\begin{array}{c}\text { Integração as dimensões } \\
\text { técnica e humana na } \\
\text { tomada de decisão. }\end{array}$ & $\begin{array}{c}\text { Aprimoramento das } \\
\text { tomadas de decisões }\end{array}$ & $\begin{array}{c}\text { Estimula o } \\
\text { autoconhecimento para } \\
\text { às tomadas de decisões }\end{array}$ \\
\hline Habilidade & $\begin{array}{c}\text { Aprimora a relação } \\
\text { interpessoal entre os alunos. }\end{array}$ & $\begin{array}{c}\text { Desenvolve o trabalho } \\
\text { em equipe }\end{array}$ & Estimula a criatividade \\
\hline
\end{tabular}

Quadro 7 - Similaridades sobre a relação entre conhecimento e desempenho nos jogos de empresa Fonte: Elaborado pelos autores

Com base no conteúdo analisado, demonstrou-se relevante a utilização dos jogos simulados como complemento da teoria obtida nas organizações, em comum a todos os autores citados nesta análise, pois a prática desenvolve habilidades não oferecidas pelo aprendizado adquirido em sala de aula, observando-se a dificuldade dos acadêmicos ao se depararem em sua primeira experiência na participação de um jogo simulador em associar suas decisões com a teoria, tornando o jogo uma técnica complementar, que contribui para a formação gerencial, apesar de não terem encontrado em suas pesquisas correlação entre conhecimento teórico e desempenho prático.

\section{CONCLUSÃO}

Com os resultados alcançados nos estudos elencados neste trabalho, demonstrou não haver nenhuma correlação entre o nível de conhecimento teórico e o desempenho na prática gerencial propiciada pelos jogos de empresa. Porém foi constatado, a princípio, por Sauaia (2006) em seus estudos que os acadêmicos que possuem os mais altos níveis de conhecimento teórico ao se deparar com a prática se sentem inseguros para a tomada de decisões, e na maioria das vezes não apresentam o melhor desempenho ao gerenciar uma organização.

Logo após, o mesmo estudo foi reaplicado por Alvarenga Oliveira (2009) e Motta (2012) que vieram a corroborar com os estudos de Sauaia (2006) demonstrando não haver a correlação entre conhecimento teórico e desempenho prático. No entanto, observa-se em todo o estudo, que no cenário contemporâneo não se pode dissociar a teoria da prática, visto que o método expositivo gera o conhecimento para os acadêmicos, porém competências, habilidades e atitudes como criatividade, inovação, visão holística, adaptação à transformação, comunicação eficaz, entre outras são recursos gerados pela participação em jogos de empresa. O jogo aprimora o pensamento estratégico dos acadêmicos, fazendo com que consigam interpretar cenários e situações.

Os jogos simulados surgem como uma nova prática de ensino, podendo ser considerada um método inovador, que auxilia e facilita o processo de inserção competitiva de acadêmicos no mercado de trabalho atual, trazendo para os mesmos o conhecimento cada vez mais relevante para a sociedade e organizações, podendo 
proporcionar uma base de vantagem competitiva na empresa em que atua.Passam a ser considerados ativos intangíveis, determinante para a competitividade da organização, difícil de imitar, transferir, comprar, vender ou substituir. Do outro lado, as universidades que perceberem esta inovação como diferencial competitivo, obterão uma nova competência e destaque no meio em que atuam, visto o ramo da educação estar altamente competitivo com a globalização.

Como afirmado por Marion e Marion (2006) quando destacou a necessidade de novo posicionamento no mercado por parte das Universidades, se preocupando com a inclusão de disciplinas de integração da teoria à prática devido à política do Ministério da Educação de flexibilização para abertura de cursos superiores aliada a novas diretrizes curriculares.

Quanto às limitações do estudo destaca-se o fato de ter sido uma pesquisa de fundo bibliográfico, com coleta de dados secundários. Outra limitação deve-se ao fato de termos restringido esse estudo à autores e pesquisas desenvolvidas no Brasil, não tendo contemplado o estado da arte. Como recomendações de estudo, sugere-se que seja cruzada a percepção de outros atores também envolvidos no estudo de jogos de empresas. E por fim, é importante que esta análise seja realizada por meio da avaliação do crescimento da teoria no meio acadêmico com maior amplitude.

\section{REFERÊNCIAS}

GOLDSCHMIDT, Paulo C. Simulação e jogo de empresas. Revista de Administração de Empresas. Rio de Janeiro, v.17, n.3, p.43-46, mai/jun. 1977.

GRAMIGNA, Maria Rita M. Jogos de Empresa. São Paulo: Makron Books, 1993.

KALLÁS, D. A utilização dos jogos de empresas no ensino da administração. VI SEMEAD - Universidade de São Paulo, 2003.

KAY, John. Fundamentos do Sucesso Empresarial. Rio de Janeiro: Campus, 1996.

MARION, José Carlos; MARION, Arnaldo Luís Costa. Metodologias de Ensino da Área de Negócios. São Paulo: Atlas, 2006.

MARINHO, Raul. Prática na teoria: Aplicações da teoria dos jogos e da evolução aos negócios. São Paulo: Saraiva, 2011.

MARTINS, Vidigal Fernandes; PEREIRA, Vinícius Silva. Um ensaio teórico: A teoria Resource-Based View e a teoria Dynamic Capabilities. Pato de Minas, 2011.

MOTTA, Gustavo; QUINTELLA, Rogério H.; MELO, D.R. Jogos de empresas: Componente curricular ou elemento da didática? In:XXXIV Encontro da ANPAD, 2010.

OLIVEIRA, P. H.; ALMEIDA, P. P.; LACERDA, J. M. Práticas de inteligência competitiva no setor varejista de Belo Horizonte: Um estudo exploratório. In: $20^{\circ}$ Congresso Internacional de Administração, 2007, Ponta Grossa: UEPG, 2007.

OSBORNE, Martin J. ; RUBINSTEIN, Ariel. A course game theory, 1994.

PEREIRA, Maise Soares; FORTE, Sérgio Henrique A. C.Visão baseada em recursos nas instituições de ensino superior de Fortaleza: Uma análise ex-ante e ex-post à LBD /96. In: Revista de Administração Contemporânea, v. 12, n.1, Curitiba: Jan-mar 2008. 
SANTOS, Roberto Vatan dos. Jogos de empresa aplicados ao processo de ensino e aprendizagem de contabilidade. In: Revista Contabilidade e Finanças - USP, n.31, p.78-95, São Paulo: Jan/Abr. 2003.

SAUAIA, Antônio Carlos A. Conhecimento Versus Desempenho das Organizações: Um Estudo Empírico com Jogos de Empresas. In: Revista de Administração, v.12, n.1, edição 49, São Paulo: jan-fev 2006.

SAUAIA, Antônio Carlos A. Satisfação e Aprendizagem em Jogos de Empresas: Contribuições para Educação Gerencial. Tese (Doutorado). Faculdade de Economia, Administração e Contabilidade. Universidade de São Paulo, São Paulo: USP, 1995.

SOUZA, Antônia Vieira; CHAGAS, Fábio Azevedo; SILVA, Carlos Eduardo. Jogos de empresas como ferramenta de treinamento e desenvolvimento. In: Revista Campus, v.2, n.1, Paripiranga: março 2009.

TEECE, D.J.; PISANO, G.; SHUEN, A. Dynamic capabilities and strategic management. Strategic Management Journal, v.18, 509-533, 1997.

TIERGARTEN, Michele; ALVES, Carlos Alberto. A visão baseada em recursos como estratégia empresarial. In: Ver. Universo Administração, v.2, ano 2, p. 61-74, jan-jun 2008.

TITTON, Luís A. Jogos de empresas: Decisões de carteira em um jogo de bancos. Dissertação (Mestrado). Faculdade de Economia, Administração e Contabilidade de Ribeirão Preto. Ribeirão Preto: 2006.

VASCONCELOS, F.; CYRINO, A. Vantagem competitiva: os modelos teóricos atuais e a convergência entre estratégia e teoria organizacional. In: Revista de Administração de Empresas, v.40, n.4, 2000.

WARSCHAUER, Claus L. Jogo de empresas na área de produção: Programa e controle da produção. In: Revista de Administração de Empresas. São Paulo, v.17, n.3, p.47-48, mai/jun. 1977. 